\title{
INFLUÊNCIA DA ADIÇÃO DE FARINHA INTEGRAL DE AVEIA, FLOCOS DE AVEIA E ISOLADO PROTEICO DE SOJA NA QUALIDADE TECNOLÓGICA DE BOLO INGLÊS
}

\author{
MARCIO SCHMIELE* \\ LEOMAR HACKBART DA SILVA** \\ PAULA FERNANDA PINTO DA COSTA*** \\ ROSANE DA SILVA RODRIGUES**** \\ YOON KIL CHANG****
}

\begin{abstract}
Avaliou-se a qualidade de bolos elaborados com substituição parcial da farinha de trigo por isolado proteico de soja na faixa de 0 a $12 \%$ e mistura de farinha integral de aveia e flocos de aveia na faixa de 0 a $40 \%$, mediante metodologia de superfície de resposta. Avaliaram-se características físico-químicas como composição centesimal e granulometria das matérias-primas utilizadas e as qualidades reológicas da farinha de trigo (farinografia e alveografia). Os resultados indicaram produto com melhor simetria e textura com menor firmeza quando incorporada aveia e melhor volume específico com o incremento de isolado proteico de soja. A análise sensorial indicou a viabilidade de produção dos bolos com ingredientes funcionais por meio da aceitação do produto pelos julgadores e intenção de compra.
\end{abstract}

PALAVRAS-CHAVE: BOLO; PROTEÍNA DE SOJA; $\beta$-GLUCANA; AVEIA.

* Químico de Alimentos, Mestre em Tecnologia de Alimentos, Doutorando em Tecnologia de Alimentos, Faculdade de Engenharia de Alimentos, Universidade Estadual de Campinas (UNICAMP), Campinas, SP (e-mail: marcio.ufpel@ gmail.com).

** Engenheiro Agrônomo, Mestre em Ciência e Tecnologia Agroindustrial, Doutor em Tecnologia de Alimentos, UNICAMP, Campinas, SP (e-mail: leomar_hs@yahoo.com.br).

*** Engenheira Agrônoma, Mestre em Tecnologia de Alimentos, UNICAMP, Campinas, SP (e-mail: costapfp83@gmail. com).

**** Professora, Doutora em Tecnologia de Alimentos, Departamento de Ciência de Alimentos, Universidade Federal de Pelotas, Pelotas, RS (e-mail: rosane.rodrigues@ufpel.edu.br).

**** Professor, Doutor em Tecnologia de Alimentos, Departamento de Tecnologia de Alimentos, UNICAMP, Campinas, SP (e-mail: yokic@fea.unicamp.br). 


\section{INTRODUÇÃO}

A incorporação de ingredientes que apresentem propriedades funcionais nos alimentos tem sido alvo de pesquisas. Entre esses encontram-se a aveia e a soja, principalmente pelo conteúdo de fibras e proteínas, respectivamente. Além de fornecer aporte energético e nutricional equilibrado em aminoácidos, ácidos graxos, vitaminas, minerais e fibras alimentares (WEBER, GUTKOSKI e ELIAS, 2002; BUTT et al., 2008), a aveia contém antioxidantes como tocoferol, ácido cafeico, ácido ferúlico e avenasterol (BIDLACK e OMAYE, 1994).

A $\beta$-glucana encontrada na aveia é uma fibra solúvel e seu consumo diário de 3 gramas pode reduzir o risco de doenças cardiovasculares, diabetes, hipertensão e obesidade (ANDERSON, 1993). Além disso, diminuem as concentrações séricas de colesterol total, lipídios totais e triglicerídeos de forma significativa, e aumentam a fração de colesterol Hight Density Lipoprotein (HDL) (SALEHIFAR e SHAHEDI, 2007). O referido consumo de $\beta$-glucana pode ser obtido pela ingestão diária de 40 gramas de farelo de aveia ou 60 gramas de farinha integral de aveia ou flocos de aveia (FLORES, BASTOS e CHANG, 2000).

A soja tem sido identificada como boa fonte de proteína e seu consumo está relacionado com benefícios à saúde pela redução do colesterol no plasma sanguíneo em indivíduos com alto nível de colesterol, diminuindo o risco de doenças cardíacas (CARRÃO-PANIZZI, GÓES-FAVONI e KIKUCHI, 2004; LIU, 2004; BARBOSA, LAJOLO e GENOVESE, 2006). Em outubro de 1999 foi aprovada pelo Food and Drug Administration (FDA), a veiculação nos rótulos das embalagens dos grãos de soja e produtos contendo grãos de soja a afirmação sobre os benefícios à saúde decorrentes do consumo de soja (FDA, 1999).

Grande parte dos produtos de panificação são compostos por ingredientes que desempenham funções específicas no método de formação da massa, embora possam variar em grau de importância no processo de sua fabricação (GUTKOSKI e PEDÓ, 2000). Um dos fatores mais importantes para o sucesso na produção de bolos deve-se à quantidade de ar incorporado na massa e ao diâmetro dessas bolhas de ar. Assim, entre as principais qualidades dos bolos encontram-se a massa de baixa densidade e produto final com baixa simetria e maior volume (STAUFFER, 1991; MARCOTTE et al., 2004).

O objetivo do presente trabalho foi averiguar a influência da incorporação de isolado proteico de soja (IPS), farinha integral e flocos de aveia em substituição parcial à farinha de trigo na produção de bolos através de Metodologia de Superfície de Resposta do tipo composto central rotacional.

\section{MATERIAL E MÉTODOS}

\subsection{MATÉRIA-PRIMA}

A farinha integral de aveia e os flocos de aveia foram cedidos pela SL Cereais e Alimentos, o IPS pela empresa The Solae Company, o leite em pó integral com 4,70\% de umidade pela ALIBRA Ltda. e os demais ingredientes pela Planta Piloto de Panificação da Faculdade de Engenharia de Alimentos da Universidade Estadual de Campinas UNICAMP).

\subsection{CARACTERIZAÇÃO FÍSICO-QUÍMICA DA MATÉRIA-PRIMA}

A composição centesimal da farinha de trigo, farinha integral de aveia, flocos de aveia e IPS foi quantificada por meio dos percentuais de umidade, proteína bruta, extrato etéreo, cinzas e fibra bruta, utilizando-se os métodos 44-15A, 46-13, 30-25, 08-01 e 32-10 da AACC (1995a; 1995b) respectivamente. $O$ teor de carboidratos foi calculado por diferença.

A granulometria da farinha de trigo foi determinada em aparelho Produtest equipado com 5 peneiras, com aberturas de 1,0 mm (US no 20), 0,500 mm (US no 35), 0,25 mm (US no 60), $0,177 \mathrm{~mm}$ (US no 80) e 0,149 mm (US no 100) conforme a RDC 326, de 22 de setembro de 2005, da ANVISA (BRASIL, 2005b). O tempo de vibração foi de 30 minutos com o reostato na posição 9 das 10 posições que o compõem. As frações do material retido nas peneiras foram expressas em porcentagem. Na determinação da granulometria de farinha integral de aveia e flocos de aveia adotou-se a mesma norma utilizada para a farinha de trigo, uma vez que não existe especificação técnica para esses produtos. 


\subsection{AVALIAÇÕES DAS PROPRIEDADES REOLÓGICAS DA FARINHA DE TRIGO}

A farinha de trigo foi caracterizada quanto às suas propriedades farinográficas e alveográficas utilizando-se, respectivamente, os métodos 54-10 e 54-30A da AACC (1995a).

\subsection{DELINEAMENTO EXPERIMENTAL}

Os ensaios para a elaboração dos bolos foram realizados por meio de Delineamento Composto Central Rotacional (DCCR) com fatorial completo $2^{2}, 4$ ensaios nas condições axiais e 4 repetições nos pontos centrais (RODRIGUES e IEMMA, 2005). Foram consideradas como variáveis independentes os teores de IPS e a mistura de farinha integral de aveia e aveia em flocos (FFA) na proporção de 1:1, cujos respectivos níveis estão apresentados na Tabela 1. As variáveis dependentes foram as características físico-químicas (simetria, volume específico, cor do miolo e umidade) e textura instrumental. O produto otimizado foi submetido à análise sensorial acompanhada da amostra padrão.

\section{TABELA 1 - NÍVEIS DAS VARIÁVEIS INDEPENDENTES DO DELINEAMENTO ESTATÍSTICO PARA ELABORAÇÃO DE BOLO COM INCORPORAÇÃO DE ISOLADO PROTEICO DE SOJA E MISTURA DE FARINHA INTEGRAL DE AVEIA E FLOCOS DE AVEIA}

\begin{tabular}{clccccc}
\hline & Variáveis & \multicolumn{4}{c}{ Níveis } \\
\cline { 3 - 6 } & Teor de isolado proteico de soja (\%) & $-\boldsymbol{\alpha}$ & $\mathbf{- 1}$ & $\mathbf{0}$ & $\mathbf{+ 1}$ & $\boldsymbol{+} \boldsymbol{\alpha}$ \\
\hline $\mathrm{X}_{1}$ & Teor da mistura de farinha integral de aveia & 0 & 2,0 & 6,0 & 10,0 & 12,0 \\
$\mathrm{X}_{2}$ & 0 & 6,0 & 20,0 & 34,0 & 40,0 \\
\hline
\end{tabular}

$\pm[\alpha]=1,41$

O tamanho das partículas e a concentração da massa são fatores que influenciam significativamente a viscosidade, a densidade e a textura de produtos à base de carboidratos. Teores elevados de partículas extremamente finas nas misturas podem prejudicar a estrutura interna do bolo (miolo), tornando-a úmida e gomosa (IWUOHA e NWAKANMA, 1998). Tentando minimizar esse problema foi utilizada a mistura de FFA.

\subsection{PROCESSAMENTO DOS BOLOS}

Aformulação para a elaboração dos bolos foi baseada em Borges et al. (2006) com modificação apenas na quantidade de sacarose adicionada, ocorrendo aumento de 86,7 para $100 \%$ em relação à farinha de trigo. Os ingredientes e suas respectivas quantidades estão expostos na Tabela 2. As quantidades de IPS e FFA foram estabelecidas no delineamento experimental descrito no item 2.4. Calculou-se a quantidade de água a ser adicionada de modo a estabelecer condição de reconstituição do leite em pó integral considerando a umidade da farinha de trigo, do IPS e da FFA.

TABELA 2 - FORMULAÇÃO BASE DO BOLO PARA EXECUÇÃO DOS ENSAIOS

\begin{tabular}{lc}
\hline \multicolumn{1}{c}{ Ingredientes } & Quantidades \\
\hline Farinha de trigo & $100 \mathrm{~g}$ \\
Sacarose & $100^{*}$ \\
Ovo in natura & $40^{*}$ \\
Gordura vegetal hidrogenada & $20^{*}$ \\
Fermento químico & $3,3^{*}$ \\
Leite em pó integral & $11,2^{*}$ \\
\hline
\end{tabular}

* Percentual em relação à farinha de trigo.

A elaboração dos bolos foi realizada em batedeira planetária Kitchen Aid Professional, modelo K45SS, sendo misturados inicialmente a gordura e o ovo durante 2 minutos na velocidade 
máxima. Em seguida, foram adicionados os demais ingredientes e misturados por 1 minuto na velocidade máxima.

A massa, em porções de 300 gramas, foi forneada em formas de alumínio com dimensões de 210 x $102 \mathrm{~mm}$ e capacidade de $650 \mathrm{~mL}$. Efetuou-se o forneamento em forno Rotational CombiDämpfer CM $101 \mathrm{G}$ a $160 \pm 2^{\circ} \mathrm{C}$ por 35 minutos.

\subsection{CARACTERÍSTICAS TECNOLÓGICAS DOS BOLOS}

\subsubsection{Simetria e volume específico}

A avaliação da simetria e do volume específico dos bolos foi realizada conforme o método 10-90 da AACC (1995a).

\subsubsection{Cor do miolo}

Avaliou-se a cor do miolo dos bolos pelo método triestímulos do sistema CIELab, utilizandose colorímetro modelo Color Quest II, marca Hunter Lab. Os parâmetros operacionais durante a análise foram: ângulo $10^{\circ}$, iluminante D65 e modo de calibração RSIN (MINOLTA, 1994).

\subsubsection{Textura instrumental}

A textura dos bolos foi determinada utilizando-se o aparelho Texturômetro TA-XT2i (Stable Micro Systems, Haslemere, Surrey, Inglaterra), com probe cilíndrico P/75, no modo Hold until time, velocidade pré-teste $1.0 \mathrm{~mm} / \mathrm{s}$, velocidade teste $1.0 \mathrm{~mm} / \mathrm{s}$, velocidade pós-teste $10.0 \mathrm{~mm} / \mathrm{s}$, distância $25 \%$ e tempo 60s para a avaliação do parâmetro de firmeza (STABLE, 1997) 24 horas após sua elaboração. Os bolos foram cortados em fatiadora G.PANIZ, Modelo FP353, com espessura de $10 \mathrm{~mm}$, sendo utilizadas 2 fatias para cada análise.

\subsubsection{Umidade}

Determinou-se a umidade dos bolos pelo método 44-15A da AACC (1995b).

\subsection{ANÁLISE SENSORIAL DOS PRODUTOS TECNOLOGICAMENTE OTIMIZADOS}

As amostras foram apresentadas individualmente e analisadas sensorialmente por 35 julgadores não treinados (alunos de pós-graduação do Departamento de Tecnologia de Alimentos da UNICAMP) pelo método descritivo com teste de avaliação de atributos mediante escala hedônica estruturada de 9 pontos ( 1 = "desgostei extremamente" a 9 = "gostei extremamente"). Os atributos avaliados foram a aparência dos bolos inteiros e, cor, textura, aroma e sabor das fatias dos bolos. Além disso, verificou-se a intenção de compra dos julgadores em relação ao produto, mediante escala de atitude de 5 pontos $(1=$ "certamente não compraria" a 5 = "certamente compraria"), conforme STONE e SIDEL (1993).

\subsection{ANÁLISE ESTATÍSTICA}

O programa Statistica 5.0 (STATISTICAL, 1995) foi utilizado para calcular os coeficientes de regressão e efetuar a análise de variância (ANOVA) para construir as superfícies de respostas, com nível de significância de $5 \%$ e obtenção dos modelos matemáticos. O valor mínimo do coeficiente de determinação $\left(R^{2}\right)$ adotado para o presente trabalho foi de 0,7 . O mesmo programa estatístico foi utilizado para os resultados da análise sensorial, efetuando-se a análise de variância e o teste Tukey $(p<0,05)$ para comparação de médias.

\section{RESULTADOS E DISCUSSÃO}

\subsection{CARACTERIZAÇÃO FÍSICO-QUÍMICA DA MATÉRIA-PRIMA}

Os resultados obtidos na composição centesimal estão apresentados na Tabela 3. Conforme a Instrução Normativa $n^{\circ}$ 8, de 02 de junho de 2005 (BRASIL, 2005a), a farinha de trigo pode ser classificada como Tipo 1 devido ao seu conteúdo de umidade, cinzas e proteínas (inferior a 15\% para umidade, 0,8\% para cinzas e maior que 7,5\% para proteína, ambos em base seca). 
O teor de cinzas está diretamente relacionado ao grau de extração e rendimento da farinha durante a moagem, interfere no tamanho das partículas da farinha e tende a apresentar coloração mais escura. Também exerce impacto direto no teor proteico da farinha, uma vez que ambos se encontram em maior concentração na camada de aleurona do grão de trigo (HOSENEY, 1990).

\section{TABELA 3 - COMPOSIÇÃO FÍSICO-QUÍMICA DA FARINHA DE TRIGO, FARINHA INTEGRAL DE AVEIA, FLOCOS DE AVEIA E ISOLADO PROTEICO DE SOJA, EM BASE ÚMIDA}

\begin{tabular}{ccccc}
\hline Amostra & $\begin{array}{c}\text { Farinha de trigo } \\
(\%)\end{array}$ & $\begin{array}{c}\text { Farinha integral } \\
\text { de aveia }(\%)\end{array}$ & $\begin{array}{c}\text { Flocos de aveia } \\
(\%)\end{array}$ & $\begin{array}{c}\text { Isolado proteico } \\
\text { de soja }(\%)\end{array}$ \\
\hline Umidade & $12,51 \pm 0,10$ & $10,61 \pm 0,04$ & $10,33 \pm 0,08$ & $5,46 \pm 0,04$ \\
Proteína bruta & $12,29 \pm 0,05$ & $20,08 \pm 0,12$ & $19,25 \pm 0,38$ & $90,23 \pm 0,25$ \\
Extrato etéreo & $1,97 \pm 0,09$ & $7,90 \pm 0,02$ & $8,68 \pm 0,09$ & $1,01 \pm 0,03$ \\
Fibra bruta & $0,18 \pm 0,03$ & $13,32 \pm 0,02$ & $13,05 \pm 0,04$ & $0,00 \pm 0,00$ \\
Cinzas & $0,61 \pm 0,01$ & $1,13 \pm 0,01$ & $2,05 \pm 0,06$ & $3,30 \pm 0,01$ \\
Carboidratos $^{*}$ & 72,44 & 45,61 & 46,64 & 0,00 \\
\hline
\end{tabular}

Média aritmética de três repetições \pm desvio padrão.

${ }^{*}$ Calculado por diferença $=100$ - (umidade + proteína bruta + extrato etéreo + fibra bruta + cinzas).

A composição da farinha integral de aveia e dos flocos de aveia mostrou-se semelhante. Esses resultados estão de acordo com os citados por Pedó e Sgarbieri (1997) e Gutkoski e ElDash (1999). A aveia e seus derivados apresentam excelente valor nutricional, destacando-se entre os cereais pelo seu teor e qualidade proteica. Apresentam excelente composição de aminoácidos essenciais estabelecida pela FAO (Food and Agriculture Organization), alto teor de lipídios distribuídos em todo o grão, com predominância de ácidos graxos poliinsaturados. Além disso, evidenciam maiores teores de fibra alimentar em relação a outros cereais, destacando-se as fibras solúveis como as $\beta$-glucanas (SÁ, FRANCISCO e SOARES, 2000).

Valores semelhantes na composição do IPS foram encontrados por Boyacioglu (2006), tendo como principal componente as proteínas com teores de $90 \%$. Um dos principais fatores que levam ao uso do IPS é a facilidade de incorporação em formulações devido a sua alta solubilidade, além de apresentar funções emulsificantes e alta digestibilidade.

A farinha integral e os flocos de aveia apresentaram maior granulometria quando comparada à farinha de trigo (Tabela 4). Observou-se que aproximadamente $60 \%$ da farinha integral de aveia e $92 \%$ dos flocos de aveia ficaram retidos sobre as peneiras de 60 mesh $(0,250 \mathrm{~mm})$ e 20 mesh $(1,000 \mathrm{~mm})$, respectivamente, enquanto que $95,29 \%$ da farinha de trigo mostrou granulometria inferior a $0,250 \mathrm{~mm}$.

\section{TABELA 4 - CARACTERÍSTICAS GRANULOMÉTRICAS DA FARINHA DE TRIGO, FARINHA} INTEGRAL DE AVEIA E FLOCOS DE AVEIA

\begin{tabular}{ccccc}
\hline Peneira (mesh) & Abertura (mm) & $\begin{array}{c}\text { Farinha de trigo } \\
\mathbf{( \% )}\end{array}$ & $\begin{array}{c}\text { Farinha integral } \\
\text { de aveia (\%) }\end{array}$ & $\begin{array}{c}\text { Flocos de aveia } \\
\text { (\%) }\end{array}$ \\
\hline 20 & 1,000 & $0,00 \pm 0,00$ & $0,35 \pm 0,02$ & $92,52 \pm 0,03$ \\
35 & 0,500 & $0,00 \pm 0,00$ & $13,55 \pm 1,40$ & $3,69 \pm 0,08$ \\
60 & 0,250 & $4,71 \pm 0,86$ & $45,32 \pm 0,46$ & $1,51 \pm 0,13$ \\
80 & 0,177 & $65,48 \pm 1,09$ & $37,58 \pm 1,01$ & $1,83 \pm 0,21$ \\
100 & 0,149 & $3,98 \pm 0,10$ & $1,08 \pm 0,01$ & $0,11 \pm 0,05$ \\
$>100$ & $<0,149$ & $25,03 \pm 0,28$ & $2,17 \pm 0,18$ & $0,33 \pm 0,01$ \\
\hline
\end{tabular}

Média aritmética de três repetições \pm desvio padrão.

A distribuição do tamanho das partículas influencia a capacidade da farinha para absorver água, sendo que as partículas menores absorvem proporcionalmente mais água e mais rapidamente que as maiores. Entretanto, a uniformidade na granulometria é mais importante que o próprio tamanho das partículas, pois favorece melhor distribuição da água pela massa (HOSENEY e ROGERS, 1990). 


\subsection{PROPRIEDADES REOLÓGICAS DA FARINHA DE TRIGO}

Farinhas com absorção de água maior que $58 \%$ e tempo de desenvolvimento acima de 10 minutos podem ser classificadas como muito fortes, no entanto, devem apresentar estabilidade mínima de 15 minutos e índice de tolerância máxima de 10 UF (PIZZINATTO et al., 1996). Com base nessas informações e analisando os valores apresentados na Tabela 5, a farinha utilizada foi classificada como forte, tendo normalmente alta absorção de água, maior tempo de desenvolvimento da massa, alta estabilidade e baixo índice de tolerância à mistura.

TABELA 5 - CARACTERÍSTICAS FARINOGRÁFICAS DA FARINHA DE TRIGO

\begin{tabular}{lc}
\hline \multicolumn{1}{c}{ Parâmetro } & Valores \\
\hline Absorção de água a 500 UF* $(\%)$ & 61,8 \\
Tempo de chegada (min) & 1,2 \\
Tempo de desenvolvimento (min) & 16,0 \\
Estabilidade (min) & 14,8 \\
Tempo de saída (min) & 19,5 \\
${\text { ITM** }\left(\mathrm{UF}^{*}\right)}$ & 30 \\
\hline
\end{tabular}

*UF = unidades farinográficas.

** Índice de tolerância à mistura.

Os resultados de alveografia da farinha de trigo indicaram W de $170,6 \times 10^{-4}$ joules, $\mathrm{P}$ de $100,4 \mathrm{~mm}$, L de $36 \mathrm{~mm}$ e $P / L$ de 2,8. Farinhas com W maiores que $160 \times 10^{-4}$ joules e $P / L$ acima de 0,55 são consideradas como farinhas fortes.

$\mathrm{Na}$ elaboração de bolos deve-se utilizar farinhas com W entre 60 e 80 (PIZZINATTO, MAGNO e CAMPAGNOLLI, 1996). Sendo assim, é aconselhável o uso de farinhas fracas, pois esse tipo de produto deve apresentar estrutura interna mais leve e porosa, menos dependente das proteínas formadoras do glúten como no caso do pão (EL-DASH e GERMANI, 1994). Isto pode ser obtido mediante adição de outros ingredientes que provocam a redução da força do glúten, proporcionando mistura ajustada para a produção de bolos como a farinha integral de aveia (BORGES et al., 2006).

\subsection{CARACTERÍSTICAS TECNOLÓGICAS DOS BOLOS}

A Tabela 6 apresenta os resultados obtidos para os parâmetros de simetria, volume, cor do miolo, textura e umidade do bolos.

\subsubsection{Simetria}

O desenvolvimento simétrico da massa durante o forneamento constitui característica importante no processamento de produtos de panificação. Para bolos, a simetria ideal assume valor zero, significando crescimento uniforme da massa e manutenção estrutural durante a cocção (BORGES et al., 2006).

A simetria dos bolos variou de 2,28 a $0,55 \mathrm{~cm}$ com o incremento de 0 a $40 \%$ de FFA nas formulações. $O$ modelo ajustado de regressão adotado para a simetria foi significativo $(p<0,05)$. Dentre os fatores que compõem o modelo, o IPS não apresentou diferença significativa ao passar de 0 a $12 \%$ nas formulações, enquanto a adição de FFA de 0 a $40 \%$ melhorou as características simétricas dos bolos. O coeficiente de regressão $\left(R^{2}\right) 82,51 \%$ e $F_{\text {calculado }} 9,51$ vezes maior que $F_{\text {tabelado }}$ indicam ajuste do modelo aos dados e garantem a validade das predições efetuadas. $O$ modelo ajustado de $1^{a}$ ordem a esse parâmetro é apresentado na Equação (1). A superfície gerada por meio dessa equação está representada na Figura 1(A).

$$
\text { SIMETRIA }=1,45-0,58 x_{2}
$$


T)



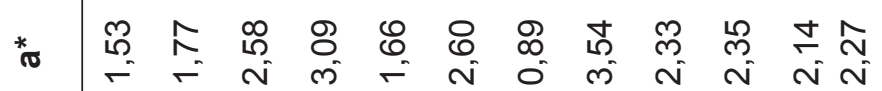



旁苞






\subsubsection{Volume específico}

Os valores para volume específico das amostras de bolos variaram de 2,17 a $2,65 \mathrm{~cm}^{3} \mathrm{~g}^{-1}$ para os diferentes ensaios. O modelo de regressão adotado não foi significativo dentro da faixa estudada, embora apresente $p$-valor $<0,001$. O coeficiente de regressão $\left(R^{2}\right)$ de $64,93 \%$ e $F_{\text {calculado }}$ 3,73 vezes maior que $F_{\text {tabelado }}$ não indicam a validade das predições efetuadas.

Embora não significativos, os resultados obtidos de volume específico sugerem que a composição química da farinha integral de aveia e os flocos de aveia interferiram na formação e agregação da estrutura proteica ao redor das bolhas de ar na massa, contribuindo para a redução de volume do produto final. Além da quantidade de ar incorporado na massa, o tamanho das bolhas de ar também é muito importante. Esse tamanho vai depender do raio, da tensão superficial e da pressão interna. Sabe-se que quanto menor o raio maior é a pressão e que geralmente o tamanho da bolha de ar no produto final é 3 a 5 vezes maior em relação à massa (KATINA, 2003).

\subsubsection{Cor do miolo}

Acordosalimentos constitui um dos atributos mais importantes observados pelos consumidores podendo influenciar a decisão de compra, assim como representa indicador de pigmentos durante 0 escurecimento não enzimático e o processo de caramelização (IBANOGLU, 2002).

O modelo ajustado para o componente $L$ (luminosidade) da cor do miolo dos bolos mostrou-se estatisticamente significativo $(p<0,05)$. Dentre os fatores estudados, a adição de IPS não apresentou influência significativa nesse parâmetro, enquanto que a incorporação de FFA de 0 a $40 \%$ proporcionou decréscimo na luminosidade dos bolos com variação de 77,23 para 68,94. A diminuição da luminosidade é resultado da incorporação de produtos integrais, pois devido às suas características proporcionam tonalidade escura de maior intensidade nos produtos em que estão presentes. O coeficiente de regressão $\left(R^{2}\right)$ de $87,66 \%$ e $F_{\text {calculado }} 14,32$ vezes maior que $F_{\text {tabelado }}$ indicam ajuste do modelo aos dados e garantem a validade das predições efetuadas. $O$ modelo ajustado de $1^{\mathrm{a}}$ ordem para a luminosidade é apresentado na Equação (2). A superfície gerada por esse modelo pode ser visualizada na Figura 1(B).

$$
\mathrm{L}=72,91-2,73 \mathrm{x}_{2} \quad \text { Eq. (2) }
$$

A coloração "a" do miolo dos bolos apresentou valores de 0,89 a 3,54, o que mostra ligeira tendência ao vermelho. Esse comportamento foi observado tanto pelo incremento de IPS quanto de FFA na faixa estudada. Através do modelo ajustado para o parâmetro "a" da cor do miolo observouse diferença significativa $(p<0,05)$. O coeficiente de regressão $\left(R^{2}\right)$ de $93,60 \%$ e $F_{\text {calculado }} 15,43$ vezes maior que $F_{\text {tabelado }}$ indicam ajuste do modelo aos dados validando as predições efetuadas. $O$ modelo ajustado de $1{ }^{a}$ ordem para o parâmetro "a" da cor é apresentado na Equação (3) e a superfície gerada por esse modelo pode ser observada na Figura 1(C).

$$
a=2,23+0,26 x_{1}+0,76 x_{2} \quad \text { Eq. (3) }
$$

Os valores obtidos em "b" da cor estão entre a faixa de 24,50 e 26,97, apresentando tendência à tonalidade amarela no miolo dos bolos com o aumento de IPS e de FFA na faixa estudada. O modelo ajustado para o parâmetro foi significativo $(p<0,05)$. O coeficiente de regressão $\left(R^{2}\right)$ de $72,41 \%$ e $\mathrm{F}_{\text {calculado }} 2,77$ vezes maior que $\mathrm{F}_{\text {tabelado }}$ indicam ajuste do modelo aos dados e garantem a validação das predições efetuadas. O modelo ajustado de $1^{\text {a }}$ ordem para o parâmetro "b" da cor é apresentado na Equação (4) e a superfície gerada por esse modelo encontra-se na Figura 1(D).

$$
b=25,78+0,38 x_{1}+0,57 x_{2}
$$

O croma do miolo ficou na faixa de 24,51 e 27,20 , observando-se aumento com a adição de IPS e FFA na faixa estudada. O modelo ajustado para esse parâmetro foi significativo $(p<0,05)$. Embora o valor de $F_{\text {calculado }} 3,11$ vezes maior que $F_{\text {tabelado }}$ seja baixo, o coeficiente de regressão $\left(R^{2}\right)$ de $74,63 \%$ indica ajuste do modelo aos dados validando as predições efetuadas. O modelo ajustado de $1^{\text {a }}$ ordem para o croma é apresentado na Equação (5) e a superfície gerada pelo modelo pode ser observada na Figura 1(E).

$$
\text { Croma }=25,89+0,40 x_{1}+0,63 x_{2} \quad \text { Eq. (5) }
$$




\subsubsection{Umidade}

Os percentuais de umidade variaram de 37,27 a 34,81 com a incorporação de IPS e FFA na faixa estudada. No entanto, com $F_{\text {calculado }}$ de apenas 3,53 vezes maior que $F_{\text {tabelado }}$ e coeficiente de regressão $\left(R^{2}\right)$ de $63,68 \%$, os valores não são significativos. Valores semelhantes de umidade foram encontrados por Moscatto, Prudêncio-Ferreira e Hauly (2004) quando incorporaram farinha de yacon e inulina na formulação de bolos de chocolate.

\subsubsection{Textura instrumental}

O modelo ajustado para a firmeza foi significativo $(p<0,05)$. Dentre os fatores estudados, a adição de IPS não apresentou influência significativa nesse parâmetro, enquanto que a incorporação de FFA de 0 a 40\% proporcionou decréscimo na firmeza dos bolos de 2408,88 para 1163,61 gramas. O incremento de fibras nas farinhas utilizadas em produtos de panificação diminui sua dureza, uma vez que proporcionam estrutura mais leve (EL-DASH e GERMANI, 1994). O coeficiente de regressão $\left(R^{2}\right)$ de $77,37 \%$ e $F_{\text {calculado }} 6,89$ vezes maior que $F_{\text {tabelado, indicam ajuste do modelo aos }}$ dados, o que garante a validação das predições efetuadas. O modelo ajustado de $1^{\mathrm{a}}$ ordem para a firmeza é apresentado na Equação (6) e a superfície gerada pode ser observada na Figura 1(F).

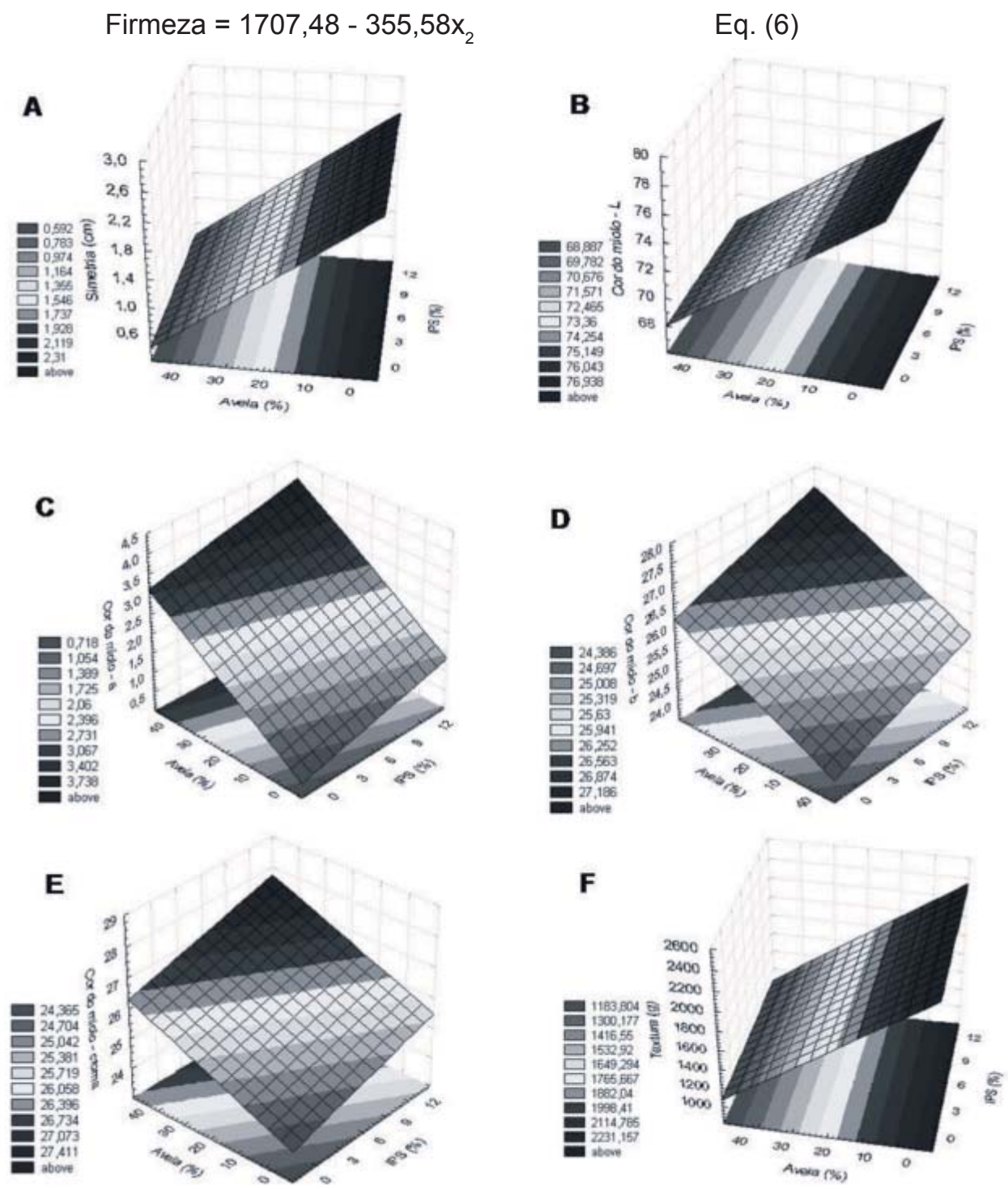

FIGURA 1 - SUPERFÍCIES DE RESPOSTA DOS PARÂMETROS TECNOLÓGICOS DOS BOLOS

A - Superfície de resposta para o parâmetro de simetria $(\mathrm{cm})$ dos bolos; B - Superfície de resposta para o parâmetro cor do miolo (L) dos bolos; C - Superfície de resposta para o parâmetro cor do miolo (a) dos bolos; D - Superfície de resposta para o parâmetro cor do miolo (b) dos bolos; E - Superfícies de resposta para o parâmetro cor do miolo (croma) dos bolos; F - Superfícies de resposta para o parâmetro de textura (firmeza - g) dos bolos. 


\subsection{SELEÇÃO DOS MELHORES TRATAMENTOS PARA A ANÁLISE SENSORIAL}

Como pode ser observado nos resultados obtidos, o IPS afeta somente a cor do miolo do produto, no entanto ainda não existem parâmetros estipulados para aceitar ou rejeitar o ponto ideal desse atributo. Sabe-se também que o IPS pode atribuir várias qualidades aos produtos, tanto tecnológicas como nutricionais.

Quando se trata de alimentos nos quais são utilizados ingredientes oriundos de grãos integrais nota-se que seus produtos tendem a apresentar coloração mais escura. Sendo assim, a incorporação de FFA será de grande importância devido à sua equilibrada composição centesimal em relação a aminoácidos, ácidos graxos e fibra alimentar já justificados neste trabalho.

Analisando as superfícies de respostas obtidas pelo delineamento composto central rotacional observa-se que a adição de maior concentração de IPS e de concentrações de FFA próximos ao ponto central fornecem melhores resultados tecnológicos. Sendo assim, foram escolhidos para a análise sensorial os ensaios 2, 6 e 9 que correspondem ao percentual de 10:6, 12:20 e 6:20 de IPS e FFA, respectivamente.

\subsection{AVALIAÇÃO SENSORIAL}

Os resultados da análise sensorial estão apresentados na Tabela 7. Pode-se observar que não houve diferença significativa entre as amostras e o padrão em relação aos atributos aroma, textura e sabor. Quanto aos atributos de aparência e cor, o ensaio com $10 \%$ de IPS e $6 \%$ de FFA obteve os melhores resultados, provavelmente pelo leve escurecimento do produto proporcionado pela adição de FFA.

Quanto à intenção de compra, os três ensaios não apresentaram diferença da amostra padrão ao nível de $5 \%$ de significância. Esse resultado pode ser interpretado como satisfatório pelo aumento na ingestão de fibras e proteínas, os principais fatores que contribuem para o melhoramento do valor nutricional do produto.

TABELA 7 - RESULTADOS DA ANÁLISE SENSORIAL DO BOLO PADRÃO (P) E DOS ENSAIOS 2, 6 E 9 (TEORES DE IPS E FFA DE 10:6, 12:20 e 6:20\%, RESPECTIVAMENTE)

\begin{tabular}{lllllll}
\hline Ensaio & Aparência & Cor & Aroma & Textura & Sabor & $\begin{array}{l}\text { Intenção de } \\
\text { compra }\end{array}$ \\
\hline 2 & $7,68 \pm 1,08^{\mathrm{a}}$ & $7,48 \pm 1,31^{\mathrm{a}}$ & $7,11 \pm 1,32^{\mathrm{a}}$ & $7,48 \pm 1,13^{\mathrm{a}}$ & $7,23 \pm 1,26^{\mathrm{a}}$ & $4,17 \pm 0,75^{\mathrm{a}}$ \\
6 & $6,86 \pm 1,17^{\mathrm{b}}$ & $6,37 \pm 1,63^{\mathrm{b}}$ & $6,66 \pm 1,37^{\mathrm{a}}$ & $7,28 \pm 1,30^{\mathrm{a}}$ & $7,14 \pm 1,22^{\mathrm{a}}$ & $3,86 \pm 0,81^{\mathrm{a}}$ \\
9 & $5,85 \pm 1,59^{\mathrm{c}}$ & $7,17 \pm 1,54^{\mathrm{ab}}$ & $7,11 \pm 1,37^{\mathrm{a}}$ & $7,63 \pm 1,26^{\mathrm{a}}$ & $7,37 \pm 1,26^{\mathrm{a}}$ & $3,97 \pm 0,86^{\mathrm{a}}$ \\
$\mathrm{P}$ & $6,68 \pm 1,39^{\mathrm{b}}$ & $7,06 \pm 1,55^{\mathrm{ab}}$ & $6,94 \pm 1,24^{\mathrm{a}}$ & $7,20 \pm 1,60^{\mathrm{a}}$ & $7,03 \pm 1,29^{\mathrm{a}}$ & $3,83 \pm 1,04^{\mathrm{a}}$ \\
\hline
\end{tabular}

Média aritmética das notas de 35 julgadores \pm desvio padrão.

Médias com letras distintas na mesma coluna diferem significativamente entre si pelo Teste do Tukey ao nível de 5\% de significância.

\section{CONCLUSÃO}

Nas condições do delineamento experimental utilizado para analisar a influência das variáveis independentes sobre as propriedades físicas, físico-químicas e sensoriais de bolos, é possível concluir que:

- a adição de IPS na faixa estudada não interferiu nas características de simetria, volume específico, textura e umidade dos bolos;

- a incorporação de FFA melhora a simetria e a textura do produto;

- a adição de IPS e FFA tende a proporcionar produtos com menor luminosidade, característica importante para produtos com ingredientes integrais;

- os resultados obtidos na análise sensorial mostraram a viabilidade da incorporação do IPS e FFA nos bolos, uma vez que não afetam sua qualidade quando comparados ao padrão;

- o melhor resultado obtido mediante interpretação dos resultados de simetria, volume específico e textura instrumental ocorreu com a adição de $10 \%$ de IPS e $6 \%$ de FFA. 


\section{ABSTRACT \\ INFLUENCE OF WHOLEOAT FLOUR, OAT FLAKES AND SOY PROTEIN ISOLATE ADDITION IN POUND CAKE TECHNOLOGICAL QUALITY}

In the present work it was evaluated the quality of cakes produced with partial substitution of wheat flour with 0 to $12 \%$ of isolated soy protein and 0 to $40 \%$ of a mixture of wholeoat flour and oat flakes, by means of Response Surface Methodology. Physico-chemical characteristics such as centesimal composition and particle size of raw materials and reologic qualities (farinograph and extensograph) of wheat flour were also evaluated. The results indicated that the product with best symmetry and texture, but with less firmness, was obtained when oat was incorporated, and, in addition, with best specific volume when isolated soy protein content was added. The sensory analysis indicated the viability of cakes production with functional ingredients, highlighted by the product acceptance and purchase intention among the judges.

KEY-WORDS: CAKE; SOY PROTEIN; $\beta$-GLUCAN; OAT.

\section{REFERÊNCIAS}

1 AACC. American Association of Cereal Chemists. Approved methods of the American Association of Cereal Chemists. $9^{\text {th }}$ ed. Saint. Paul, 1995.

2 AACC. American Association of Cereal Chemists. Approved methods of the American Association of Cereal Chemists. $9^{\text {th }}$ ed. Saint. Paul, 1995.

3 ANDERSON, J.W. Fibra, doença cardiovascular e diabetes. Dieta e Saúde. v.2, n.2, p.4-5, 1993.

4 BARBOSA, A.C.L.; LAJOLO, F.M.; GENOVESE, M.I. Influence of temperature, $\mathrm{pH}$ and ionic strength on the production of isoflavone-rich soy protein isolates. Food Chemistry, v.98, n.4, p.757-766, 2006.

5 BIDLACK, W.R.; OMAYE, S.T. Natural protectants against natural toxicants in food. Lancaster, USA: Technomic Publishing, 1994. $121 \mathrm{p}$.

6 BRASIL. Ministério da Agricultura, Pecuária e Abastecimento. Instrução Normativa n8 de 02 de junho de 2005. Aprova o regulamento técnico de identidade e qualidade de farinha de trigo. Disponível em: www.agricultura.gov.br. Acesso em: 16 de janeiro de 2010.

7 BRASIL. Ministério da Saúde. Agência Nacional de Vigilância Sanitária. Resolução RDC № $\mathbf{3 2 6}$ de 22 de setembro de 2005. Aprova o regulamento técnico para produtos de cereais, amidos, farinhas e farelos. Disponível em: htpp://www.elegis.bvs.br. Acesso em: 16 de janeiro de 2010.

8 BORGES, J. T. S.; PIROZI, M. R.; LUCIA, S. M. D.; PEREIRA, P. C.; MORAES, A. R. F.; CASTRO, V. C. Utilização de farinha mista de aveia e trigo na elaboração de bolos. Boletim do CEPPA. v. 24, n. 1, p. 145-162, 2006.

9 BOYACIOGLU, M.H. Soy ingredients in baking. In: RIAZ, M.N. Soy applications in food. New York, USA: CRC Press, 2006. Chap.4, p.63-81.

10 BUTT, M. S.; TAHIR-NADEEM, M.; KHAN, M. K. I.; SHABIR, R.; BUTT, M. S. Oat: unique among the cereals. European Journal of Nutrition, v.47, n.2, p.68-79, 2008.

11 CARRÃO-PANIZZI, M. C.; GÓES-FAVONI, S. P.; KIKUCHI, A. Hydrothermal treatments in the development of isoflavone aglycones in soybean grains. Brazilian Archives of Biology and Technology, v.47, n.2, p.225-232, 2004.

12 EL-DASH, A.; GERMANI, R. Tecnologia de farinhas mistas: uso de farinhas mistas na produção de bolos. Brasília: EMBRAPASPI, 1994. 31 p. v.7.

13 FDA. Food and Drug Administration. Food labeling: health claims; soy protein and coronary heart disease. Federal Register, 64: 57699-733. Silver Spring, USA, Oct., 1999.

14 FLORES, H.E.M.; BASTOS, F.M.; CHANG, Y.K. Efeito benéfico na saúde humana das fibras dietéticas presentes nos alimentos. In: SIMPÓSIO DE ALIMENTOS FUNCIONAIS PARA O NOVO MILÊNIO, 1., 2000, Campinas. Anais... Campinas: Ed. UNICAMP, 2000. p.24-25.

15 GUTKOSKI, L.C.; EL-DASH, A.A. Efeito do cozimento por extrusão na estabilidade oxidativa de produtos de moagem de aveia. Pesquisa Agropecuária Brasileira, Brasília, v.34, n.1, p.119-127, 1999.

16 GUTKOSKI, L.C.; PEDÓ, I. Aveia: composição química, valor nutricional e processamento. São Paulo: Varela, 2000. 191 p.

17 HOSENEY, R.C. Principles of cereal science and technology. Saint. Paul: American Association of Cereal Chemists, 1990. $327 \mathrm{p}$. 
18 HOSENEY, R.C.; ROGERS, D.E. The formation and properties of wheat flour doughs. Food Science and Nutrition, v.26, n.2, p.73-93, 1990

19 IBANOGLU, E. Kinetic study in colour changes in wheat germ due to heat. Journal of Food Engineering, v. 51 p. 209 $213,2002$.

20 IWUOHA, C.I.; NWAKANMA, M.I. Density and viscosity of cold flour pastes of cassava (Manihot esculenta Grantz), sweet potato (Ipomoea batatas L. Lam.) and white yam (Dioscorea Rotundata Poir) tuber as affected by concentration and particle size. Carbohydrate Polymers, v. 37, p. 97-101, 1998.

21 KATINA, K. High-fiber baking. In: CAUVAIN, S.P. Bread making: improving quality. Cambridge, England: Woodhead Publishing, 2003. Chap. 23, p 501-513.

22 LIU, K. Soybeans as functional food and ingredients. Illinois, USA: AOCS PRESS, 2004. 331 p.

23 MARCOTTE, M.; SABLANI, S.S.; KASAPIS, S.; BAIK, O.; FUSTIER, P. The thermal kinetics of starch gelatinization in the presence of other cake ingredients. International Journal of Food Science and Technology, v. 39, p. 807-810, 2004.

24 MINOLTA CO. Precise color communication: color control from feeling to instrumentation. Osaka, Japão, 1994.49 p.

25 MOSCATTO, J.A.; PRUDÊNCIO-FERREIRA, S.H.; HAULY, M.C.O. Farinha de yacon e inulina como ingredientes na formulação de bolo de chocolate. Ciência e Tecnologia de Alimentos, v.24, n. 4, p.634-640, 2004.

26 PEDÓ, I.; SGARBIERI, V.C. Caracterização química de cultivares de aveia (Avena sativa L.). Ciência e Tecnologia de Alimentos, v. 17, n. 2, p. 78-83, 1997.

27 PIZZINATTO, A.; MAGNO, C.P.R.S.; CAMPAGNOLLI, D.M.F. Avaliação e controle de qualidade da farinha de trigo. Campinas: Instituto de Tecnologia de Alimentos/Centro de Pesquisa e Tecnologia de Cereais, 1996.

28 RODRIGUES, M.I.; IEMMA, A.F. Planejamento de experimentos e otimização de processos. Campinas: Ed. Casa do Pão, 2005. 325 p.

29 SALEHIFAR, M.; SHAHEDI, M. Effects of oat flour on dough rheology, texture and organoleptic properties of taftoon bread. Journal of Agricultural Science and Technology, v.9, p.227-234, 2007.

30 SÁ, R.M.; FRANCISCO, A.; SOARES, F.C.T. Concentração de ß-glucanas nas diferentes etapas do processamento da aveia (Avena sativa L.). Ciência e Tecnologia de Alimentos, v. 18, n. 4, p. 425-427, 1998.

31 STABLE MICRO SYSTEMS. User manual - Texture Analyser model TA-XT2i, Version 6.10 and 7.10. Vienna Court, 1997. $87 \mathrm{p}$.

32 STAUFFER, C.E. Functional additives for bakery foods. Ohio, USA: AVI Book, 1991.

33 STATISTICAL for windows. Graphics software. Tulsa, Oklahoma: STATSOFT, 1995.

34 STONE, H.; SIDEL, J.L. Sensory evaluation practices. $2^{\text {nd }}$ ed. Redwood City: Academic Press, 1993.308 p.

35 WEBER, F. H.; GUTKOSKI, L. C.; ELIAS, M. C. Processo de estabilização de farinha de aveia por imersão das cariopses em água. Brazilian Journal of Food Technology, v. 5, n. 1-2, p. 225-235, 2002.

\section{AGRADECIMENTOS}

Ao Conselho Nacional de Desenvolvimento Científico e Tecnológico (CNPq) pela concessão da bolsa de estudos. 